\title{
A short history of bodily sensation*
}

\author{
JEAN STAROBINSK I ${ }^{1}$
}

From the Faculté des Lettres, Université de Genève, Switzerland

In one of his Cahiers, Paul Valéry has the note. Somatism (heresy of the end of time),

Adoration, cult of the machine for living. ${ }^{1} \dagger$ Have we come to the end of time? The heresy anticipated by Valéry has almost become the official religion. Everything is related to the body, as if it had just been rediscovered after being long forgotten; body image, body language, body consciousness, liberation of the body are the passwords. Historians, prey to the same infection, have begun inquiring into what previous cultures have done with the body, in the way of tattooing, mutilation, celebration and all the rituals related to the various bodily functions. ${ }^{2}$ Past writers from Rabelais to Flaubert are ransacked for evidence, and immediately it becomes apparent that we are far from being the first discoverers of bodily reality. That reality was the first knowledge to enter human understanding: "They knew that they were naked' (Genesis 3.7). From then on, it has been impossible to ignore the body.

Nevertheless, body consciousness, as it is practiced and spoken of in our society, does have certain new and original aspects that it is important to bring out and whose antecedents it would be useful to set in order in sound genetic fashion. But so as not to let myself be led astray (and because I believe that the most fruitful generalizations are those arising from fairly precise studies of limited topics), I will confine myself to a somewhat circumscribed area: the internal perception of our own bodies cenesthesia - which is undeniably a component of our contemporary 'sensibility', whether among philosophers or writers, or in certain psychotherapeutic practices (e.g. Schulz's

\footnotetext{
1 Address for correspondence: Dr Jean Starobinski, Faculté des Lettres, Université de Genève, 3, Place de l' Université, 1211 Genève 4 , Switzerland.

* This article first appeared in Humanities in Review, vol. I, 1982, published by the New York Institute for the Humanities, and translated by Sarah Matthews.

$\dagger$ The notes will be found on pp. 32-33.
}

'autogenic training', relaxation, 'body contacts'), or, finally, in psychoanalytic thinking.

We shall not dwell on the theories developed by the ancients, however fascinating they might be; but let us recall a few stages of earlier thinking, before pausing a little longer over the discussions that prevailed at the end of the nineteenth century and Freud's response to them.

In Antiquity, the disciples of Aristippus of Cyrene spoke of an 'internal contact' - tactus intimus in Cicero's translation. ${ }^{3}$ Montaigne, quoting Cicero, reminds us that 'the Cyrenaics... maintain that nothing external to themselves is perceptible, and that the only things that they do perceive are the sensations due to internal contact, for example, pain and pleasure'. ${ }^{4}$

For a long while, pain and pleasure were not attributed to a specific sensory system; they were called 'bodily passions', whereas the traditional term, internal sense (sensus internus), referred to the conscious activities that the mind developed in and of itself (reason, memory and imagination) on the basis of information provided by the external senses (sight, hearing, taste, touch and smell). According to Aristotelian doctrine, the information provided by the external senses reached the internal sense only after having been unified by the common sense (sensorium commune, koinon aistheterion). ${ }^{5}$ The body was in no way forgotten; but as long as Galenic medicine prevailed, it was principally by way of the humors, and not through nervous information, that the body was capable of modifying the activity of the soul and, in turn, of being modified by the soul.

In his treatise The Passions of the Soul, Descartes put forward a clear distinction between three different categories of perception: 'that which relates to objects external to us' (art. 23), 'that which refers to our body' (art. 24), 
and 'that which refers to our soul' (art. 25). Bodily sensations were of many kinds:

The cognizings we refer to our body, or to certain of its parts, are those we have of hunger, thirst and of our other natural appetites - to which may be added pain, heat and the other affections which we sense as in our limbs, not as in external objects. ${ }^{6}$

Descartes thus analyzes and classes sensory activities as belonging to three specific areas - the body, the world and the consciousness - daily experience of which leads us to an awareness of how they coincide and are superimposed one upon the other. But Descartes's influence in this regard was not particularly great among eighteenth-century doctors. Some of them, particularly in Montpellier, were more taken by Stahl's ideas, which conferred on the viscera a sort of relative autonomy and independent sensibility. Nonetheless, some philosophers, such as Lignac, Turgot or d'Alembert, spoke with precision of a 'sense of coexistence with our bodies', of an 'internal touch' and so on. ${ }^{7}$ Some of them (for instance, Bordeu, Lacaze and Diderot) came to pick out a phrenic or diaphragmatic center, whose role merged with that of the splanchnic nexus of the sympathetic nerve. Cabanis, in 1800 , attributed great importance to the 'organic sensations' that ended in certain centers of reaction, the most important of which was, obviously, the brain. Thus, the instincts were the transformation, at the level of behavior, of the most long-standing and most persistent of organic sensations. Instinct, thus, could be seen as the motor branch of a sensorimotor connection, the sensory branch of which was made up of 'organic sensations'.

It was in 1794, in Halle, in the title of a doctoral thesis at which Johann Christian Reil presided and of which he was the inspiration, that the word coenesthesis was used for the first time. The term was equivalent to the German Gemeingefühl, for which the French equivalent subsequently became on some occasions sensibilité générale (general sensibility) and on others cénesthésie (cenesthesia). ${ }^{8}$

Reil (through the medium of his disciple Hübner) returned, without mentioning Descartes, to the tripartite division that we have already seen in The Passions of the Soul.

We encounter in the soul three sorts of representations, which differ in relation to the objects represented.
(1) Its own intellectual state, its powers, its actions, its representations and concepts; it distinguishes these things itself, and in this way becomes conscious of itself.

(2) It represents to itself its external state or the relations of the whole man to the world.

(3) Finally, it represents to itself its own bodily state.

Each of these sorts of ideas, by which man is represented according to the three different types of state, is sited in the body in its own particular organic apparatus.

(1) Cenesthesia, by means of which the soul is informed of the state of its body, which occurs by means of the nerves generally distributed throughout the body.

(2) Sensation (sensatio externa). This is excited by the senses and represents the world to the soul.

(3) Finally, the activities which originate and are carried out integrally within the organ of the soul. [Organ der Seele is the term Reil uses to designate the brain.] By means of these (that is to say, by the internal sense) imagination and judgement are formed; the soul receives the representation of its powers, its ideas and its concepts, and is thus rendered conscious of itself. ${ }^{9}$

This distinction between three specific organic apparatuses can be found again at the beginning of our century, but without any direct reference to Reil, in Carl Wernicke. He proposed, as is well known, a model of psychic life that involved collaboration between an allopsyche (in relation to external objects), a somatopsyche (in relation to corporeal existence) and an autopsyche (in relation to its own system of representations). ${ }^{10}$ In Reil (as in Wernicke), this functional distinction formed the basis for a pathogenic classification. Reil not only envisaged changes in cenesthesia due to general disorders, but he allowed there to be idiopathic disorders of the cenesthesia: there were in fact cases in which the disease was limited to the nervous apparatus involved in transmitting the somatic information - in the absence of any real lesion in the visceral organs or in the brain itself. A distortion (the anatomo-pathological substratum of which Reil was entirely incapable of indicating) then sent a misleading message to the brain about the body's condition. A bodily illusion occurred-giving rise to a belief in a tumor or an abdominal parasite, depite the lack of any objective evidence. Up to a certain point, judgment could correct this false impression. But when the impression 
managed to take hold, it created a state of madness. A good hundred years before the concept of cenestopathy appeared in France (with Dupré and Camus), Reil included in his psychiatric nosology a class of ailments characterized by a primary disturbance of bodily representations. This very extensive class contained the classic examples that had occurred for the previous two or three centuries in chapters on melancholia or hypochondria: people who believed themselves to be made of glass and liable to shatter at the slightest blow or who had lost the feeling of being present within their actual bodies. Reil had no difficulty adding affective disorders or derangement of the instincts or the appetites, such as pica, bulimia and polydipsia on the one hand, and nymphomania and lubricity on the other.

'Romantic' thought readily welcomed the concept of cenesthesia. From a genetic point of view, Reil had already accorded it priority in the order of sensory activities: it was the first that appeared in the fetus. Evolutionist speculation, right up to physiologists like Purkinje, could propose the notion of a primary bodily sense from which all the other sensory activities could be seen as being differentiated developments. As the first vital sensation, cenesthesia could be considered, by some, to be the source of all psychic life, insofar as that life was made up of sensory differences. What came to prevail, among scholars or philosophers claiming to be determinists or monists, was a 'sensualist' conception of mental life, which opened the way for a sort of imperialism of cenesthesia. If mental life was determined by sensory activity, and if all sensory activity was made up of derivatives of cenesthesia, then one could finish by asserting, as Ribot did in 1884, in The Diseases of the Personality, that our personality resided entirely in the messages, partially unconscious, that derived from bodily life.

The fifteen French editions of Ribot's The Diseases of the Personality (published between 1883 and 1914) bear witness to the immense influence exerted by this book and justify a fairly close examination of the theories propounded in it.

A first assertion was based on physiology: 'Its [consciousness's] production is always associated with some activity of the nervous system.' ${ }^{11}$ In accord with the physiologists, however, Ribot allowed that a significant part of nervous activity might remain unconscious: "All nervous activity does by no means imply psychic activity nervous activity being far more extended than psychic activity. Consciousness, accordingly, is something superadded.'12 It was, but it was doomed to intermission. (Ribot underlines the term, a term to which, as is well known, Proust was to attach great importance.) The personality was thus a variable kaleidoscopic phenomenon, by very reason of the incessant fluctuation of bodily states.

If, accordingly, we admit that the organic sensations proceeding from all the tissues, organs and movements produced - in a word, from all the states of the body - are in some degree and form represented in the sensorium; and if the physical personality be only their sum total, it follows that personality must vary as they vary, and that these variations admit of all possible degrees, from simple distemper to the total metamorphosis of the individual. Instances of 'double personality' ... are but an extreme case... We should find in mental pathology enough observations to establish a progression, or rather a continuous regression from the most transient change to the most complete alteration of the ego... The ego exists only on the condition of continually changing. ${ }^{13}$

Following Ribot, Sollier proposed an interpretation of hysteria as the result of changes in cenesthesia: Séglas attributed to this same 'peripheral' mechanism states of depersonalization and melancholic deliria of negation.

One would have no difficulty in demonstrating that what one is dealing with here is an entirely theoretical construction, supported in large part by an entirely metaphorical method of argumentation. The fundamental assumption is of a causality that operates on the basis of elementary materials, in which complex phenomena are built up from simple units. Ribot refers to Taine, who himself refers to Dr Krishaber to maintain: 'The Ego, the moral person, is a product of which sensations are the prime factors'. ${ }^{14}$ To this neosensualism are added curious political metaphors, which could have flowed only from the pen of a convinced democrat. Thus, after having declared that 'in every animal the basis of its psychic individuality is the organic sense,' he adds.

But, in man and with the higher animals, the turbulent world of desires, passions, perceptions, images and ideas covers up this silent background. Except at 
given intervals, it is forgotten, from the fact that it is not known. Here the same takes place as in the order of social facts. The millions of human beings, making up a large nation, as regards itself and others, are reduced to a few thousand men, who constitute its clear consciousness, and who represent its social activity in all its aspects, its politics, its industry, its commerce and its intellectual culture. And yet these millions of unknown human beings - limited as to manner and place of existence, quietly living and quietly passing away - make up all the rest; without them there would be nothing. ${ }^{15}$

Ribot, in the closing sentences of the book, introduces terms like consensus and solidarity, which have an equally clear social resonance.

The unity of the ego, in a psychological sense, is, therefore, the cohesion, during a given time, of a certain number of clear states of consciousness, accompanied by others less clear, and by a multitude of physiological states which without being accompanied by consciousness like the others, yet operate as much and even more than the former. Unity, in fact, means coordination. The conclusion to be drawn from the above remarks is namely this, that the consensus of consciousness being subordinate to the consensus of the organism, the problem of the unity of the ego is, in its ultimate form, a biological problem. To biology pertains the task of explaining, if it can, the genesis of organisms and the solidarity of their component parts. Psychological interpretation can only follow in its wake. ${ }^{16}$

What this radical biologism lacked, without yet having at its disposal the more recent concept of the genome, was any apparatus of clinical experiments and proofs. It was hardly surprising, then, that after a brief moment of glory this 'peripheral' theory of the constitution of the ego, and above all the interpretation it suggested of disturbances of the personality, became the object of lively criticism. Ribot was the first to admit its shortcomings ${ }^{17}$ and recognized later that in attributing so great an importance to somatic sensory information, he had neglected the motor components of psychic activity. Pierre Janet $^{18}$ observed that in all the cases of depersonalization he had examined, he had never been able to demonstrate any kind of peripheral sensory disturbance and, as a corollary, that when dealing with tabetics whose bodily perceptions were seriously upset, he had not noted any psychic disturbances. To allege a disturbance in 'corporeal sensoriality' was, according to him, to remain trapped in a 'metaphysical' hypothesis. Psychopathological phenomena, such as depersonalization or a sense of emptiness, should be considered as a lack of action (or lack of the psychic energy available for action) and not as a disturbance in sensory receptivity. 'Scientific psychology must consider psychological facts as actions and express them in terms of action. A sense of emptiness is a disturbance of action and not of the sensibility nor of a poorly understood consciousness'. ${ }^{19}$ This led Janet to introduce a distinction between what he called 'primary actions' and 'secondary actions'. Primary action takes its cue from sensory stimuli, whether internal or external, and reacts directly to them; secondary action brings to primary action the reinforcement of a belief, an integrating device effective in the circumstances experienced. Pathological disturbance, in depersonalization, affects the secondary action, which can break down without the primary action showing the slightest anomaly. It is in the "relation to the real' that the real disturbance is to be found.

The affirmation of the primacy of the active response over somatic information was also characteristic of Freud's thinking. But before lingering more closely over a few significant pages of Freud, it would be appropriate to devote a moment to the theory put forward by Charles Blondel in La Conscience Morbide (1914). (Both a doctor and a philosopher, Blondel began as a careful follower of the teachings of Durkheim and Bergson; after the war, he wrote one of the first important studies of Proust and composed a hasty and disappointing work on psychoanalysis.) In La Conscience Morbide, Blondel opposed to the 'peripheral theory' an active force - and this active force was language. It was not that the cenesthetic message was nonexistent, but it was not its supposed disruption that explained the disturbances of the sick mind. According to Blondel, a purely physiological theory was incapable of explaining the phenomena observed by the clinician. The 'cenesthetic masses' (which he also called 'pure psychology') did not by themselves determine mental illness: the 'morbid' factor lay entirely in the insufficiency of the verbal response to the bodily perceptions a response worked out by the individual in the act of thinking according to the linguistic tools he has received from society. Noting, as Dupré 
had done in his studies on cenestopaths, that the mentally ill had recourse to a wealth of metaphorical formulas with which to describe their symptoms, ${ }^{20}$ Blondel sited the anomaly not in the (supposedly neutral) bodily nervous information but in a fault in the "eliminatory action' that should have resulted from a successful intervention of language. The normal mind, according to Blondel, eliminates the idiosyncratically individual, the 'pure psychology,' by putting into effect the interpretive tools and concepts provided by the system of collective representations. The law of language, which is the result of social training, has as its function the depersonalization of the expression that we give to our individual states. Blondel quoted in this respect a revealing passage from Durkheim.

There really is a part of ourselves which is not placed in immediate dependence upon the organic factor: this is all that which represents society in us. The general ideas which religion or science fix in our minds, the mental operations which these ideas suppose, the beliefs and sentiments which are at the basis of our moral life, and all these superior forms of psychic activity which society awakens in us, these do not follow in the trail of our bodily states, as our sensations and our general bodily consciousness do... This is because the world of representations in which social life passes is superimposed upon its material substratum, far from arising from it. ${ }^{21}$

Blondel concluded from this that the normal mind was a mind in which the cenesthetic factor was dominated and controlled by the impersonal system of socialized discourse. While believing himself to be asserting his ego, the rational individual was in fact affirming the triumph of collective norms. The disturbed mind, incapable of manipulating language according to these collective dictates, was a mind embroiled in the individual cenesthetic experience - in the nonverbal or the preverbal, which even the most daring play of metaphor was incapable of expressing. Blondel did not fail to remark the poetic nature of these attempts, which tended to imply that poetry was deviant from the social norms, that it was sited on the side of 'pure psychology', that it had something in common with the 'sick mind'.

It was thus not the body that imposed its law on the mind. It was society that, through the intermediacy of language, took the commands of the mind and imposed its law on the body.
Blondel's theory tended to dispose of the body as cause in order to return to it later as the agent of the expressive intentions that the individual imposed on it under the dictates of the collective consciousness. Thus, we can see interest shifting from the body as physiological object (primarily the producer of internal information destined to be filtered by language) to the body according to society (primarily carrying out messages bearing meaning, according to the collective codes and rules). Social prescriptions dictated not only language, but also nonverbal bodily manifestations; there is nothing, in the passage that follows, that could not be quoted with approval by any of the sociologists or 'paralinguists' of today who talk to us of 'the body as a medium of expression' '.22

In order to find the motor or vasomotor expression of our states of mind, we are dumbly preoccupied in seeking the right note, of finding the mime, regulated and defined by custom and propriety, corresponding to the emotion standard to which our own emotion refers. From this point of view mime seems, so to speak, to have received its morphology and its syntax from the collective... If one thinks about it hard, it becomes apparent that there is not a single one of our motor manifestations which is not thus more or less stringently defined and with regard to which there does not exist a collective model, that is to say, a motor concept, to which it has to conform. ${ }^{23}$

In writing the Traumdeutung, Freud began by running up against the generally held latenineteenth-century theories which assumed that dream activity derives from peripheral or visceral sensory excitation. Ribot, in The Diseases of the Personality, had formulated in passing a theory of the dream that was in perfect accord with the rest of his theory of the primacy of cenesthesia.

Constantly active, they [the physical bases of the personality] make up by their continuity for their weakness as psychic elements. Hence, as soon as the higher forms of mental life disappear, they pass to the front rank. A clear example of this exists in dreams (whether pleasant or painful) aroused by organic sensations, like nightmares, erotic dreams, etc. In these dreams, even with a certain degree of precision, we may assign to each organ the part that belongs to it. $^{24}$

Freud, well aware of the vast body of literature that, even before Ribot, tended in the same direction, devoted several pages of his historic Introduction to Leibreiztheorie (he used the 
term Gemeingefühl more rarely) and concluded that 'the theory of somatic stimulation has not succeeded in completely doing away with the apparent absence of determination in the choice of what dream-images are to be produced ${ }^{\prime 25} \mathrm{He}$ returned to the question again in Chapter 5 ('The Material and Sources of Dreams'), section C ('The Somatic Sources of Dreams').

Freud did not deny that 'organic impressions' played their part in the production of dreams. But he did not allow that they could be a sufficient condition and the only cause: it was not enough to invoke them to be free of the need to provide any other explanation. Like Janet, Freud was opposed to a purely physiological theory, the more so to one that might be unifactorial or unicausal, according to which dreams were seen as being merely the cerebral propagation, through loose associations, of visceral sensory stimuli. He noted that these stimuli were not always efficient; organic sensations, by definition, are never interrupted, whereas dreams are intermittent: 'These stimuli are present at all times, and... it is difficult to understand, then, why the mind does not dream continuously all through the night'. ${ }^{26}$ In a number of cases, a dream may derive solely from psychic sources. And even when the presence of somatic sensations can be admitted with a certain degree of probability, they can be seen as being simply the material to which work is then applied from quite another quarter, and that alone gives it meaning. In relation to its somatic sources, the dream is a 'reaction', an interpretive working out, and our scientific attention should be directed to that reaction; our interpretation shoud be of the act of interpretation carried out by the dreamer.

There can be no doubt that physical cenesthesia ... is among the internal somatic stimuli which can dictate the content of dreams. It can do so not in the sense that it can provide the dream's content, but in the sense that it can force upon the dream-thoughts a choice of the material to be represented... The cenesthetic feelings left over from the preceding day link themselves up, no doubt, with the psychical residues which have such an important influence on dreams. This general mood may persist unchanged in the dream or it may be mastered, and thus, if it is unpleasurable, may be changed into its opposite.

Thus, in my opinion, somatic sources of stimulation during sleep (that is to say, sensations during sleep), unless they are of unusual intensity, play a similar part in the formation of dreams to that played by recent but indifferent impressions left over from the previous day. I believe, that is, that they are brought in to help in the formation of a dream if they fit in appropriately with the ideational content derived from the dream's psychical sources, but otherwise not. They are treated like some cheap material always ready to hand, which is employed whever it is needed, in contrast to a precious material which prescribes the way in which it is to be employed. If, to take a simile, a patron of the arts brings an artist some rare stone, such as a piece of onyx, and asks him to create a work of art from it, then the size of the stone, its color and markings, help to decide what head or what scene shall be represented in it. Whereas in the case of a uniform and plentiful material such as marble or sandstone, the artist merely follows some idea that is present in his own mind. ${ }^{27}$

All that the somatic sources do, then, is provide one of the most common materials, of which the mind of the dreamer, working from other sources, will make something of its own. Freud, in his turn, has recourse to metaphors; the image of the sculptor brings us back to Aristotelian notions of causality. In Aristotelian terms, the somatic source is, in the best sense, the material cause of the dream. But the neurophysiological is not simply a neutral and anonymous substratum. The dream has meaning because of the form imposed on this substratum. This setting into form is the result of an intention, of which the active agent is called the 'spirit', the 'wish', 'dream-work'. Freud assigned a double aim to the dream: to protect sleep and to fulfil a wish. In both cases, the dream works according to its own ends, against the somatic sensation-either to neutralize it or to transform it. Accepting these postulates entails an important consequence for anyone wishing to achieve an adequate understanding of dreams. It is vain to trace dreams back to their physiological source and to invoke a particular visceral disturbance, which could be measured in terms of the strength of the painful stimuli or in variations in the cardiac rate. What one now has to understand is the new language, the original form in which this material - in itself unimportant - has been interpreted and recast by the dream. Analysis is an exegesis of the final cause of the dream: it seeks to understand what the wish is aiming for, and why.

In other words, dream analysis can be seen as 
the 'informed' interpretation of a 'naive' interpretation, which has itself been reworked at the moment of narrating the dream. But this formula is still too simple; for the somatic stimulus is the starting point for a double translation. First, it gives rise to the deployment of latent thoughts, in which the wish can express itself without reserve; then it transports itself through the distortions and puzzles of which Freud so carefully established the vocabulary in the manifest dream. The 'somatic source', the material cause, was in addition only an occasional cause, a pretext. Freud did not fail to recognize this, but he felt it unnecessary to reiterate it. This meant in effect reworking the definition of the unconscious. Despite what is fairly widely believed today, it was quite usual to speak of the unconscious before Freud's time, but it was an unconscious associated with the obscure murmurings of visceral functions, from which would emerge, intermittently, conscious acts. For Freud, the unconscious was the first interpretation of visceral stimuli, it was the latent thoughts of the dream and the process that gave form to the manifest dream. Freud's original contribution was not to have spoken first of the unconscious but to have, so to speak, lifted the monopoly held on it by organic life and to have installed it within the psychic apparatus itself. It was thus at the price of abandoning the body (in which it was definable only in terms of weakness or strength, whether organic or 'nervous') that the unconscious became the custodian of a language and the producer of palimpsests or puzzles that were then open to being deciphered. Having ceased to have the life of the body as its exclusive source, the unconscious then escaped from the exclusive competence of a medical approach and became dependent on hermeneutics.

Thus, before Durkheim and Blondel opposed to cenesthesia the conceptual categories of language set up by the collective consciousness, Freud, in 1900, opposed to cenesthesia, to 'organic stimuli', the operation of language, but a language in which the social norms were only partially represented - by censorship and interdictions. Another similarity - apart from any questions of priority - is worth noting: though the body might see itself being refused any sort of importance as a causal source of psychic disturbance, it found a crucial role for itself as the place or scene in which this disturbance manifested itself. In a vision that placed in the background the sensory information being provided by the body, and that emphasized the reaction manifested in the psychic act and in language, the body came to appear as the primary target of the act and as the primary signification worked out in the language. Just as Durkheim and Blondel, after having rejected the hypothesis of a cenesthetic source of psychosis, reestablished the importance of the body as bearer or enactor of manifestations of a gestural code of social origin, so Freud equally returned to the body, no longer considering it as explanatory source but as the place in which were carried out the expressive aims of the wish. Breuer and Freud had already taken this direction in their studies of hysteria. The case of the dream was equally clear; and among the different types of dream, the nightmare provided a typical example. ${ }^{28}$

Received medical opinion held that nightmares were the representational transposition of a purely somatic oppression. According to Freud, such a case was the exception; the greatest number of somatic sufferings felt in dreams were, on the contrary, the representation of a censored wish loaded with suffering: what could not be denied was that the suffering then expressed itself in the language of the body, though the 'source' should be sought in the psyche. The inquiry should turn from the disturbed body to the affect that was once revealed and hidden in the somatic register. The body was the wrong turn, the dead end taken by energy originating from the psyche, and to which the term intention was more appropriate than excitation.

At this point, it seems that in marking a radical difference between psychological explanation and physiological explanation, in 'dephysiologizing' psychology, Freud was 'desomatizing' the causal system commonly accepted by his predecessors. There is, in Freud's explanations, less body and more language than in the majority of his contemporaries; this explains the dissension that was to grow, at least for a while, between psychoanalysts and neurophysiologists. Freud took care never to sever the links with biology (which is far from being the case with some of those who subsequently claimed to be his followers). To be sure, what Freud retained 
of biology did not consist of experimentally measurable mechanisms but, rather, of general schemes and of supposedly permanent laws of the nervous system and living matter. If Freudian psychology became detached, to some extent, from the physiological body, metapsychology, in compensation, showed itself to be a return to physiology and to the body in an intuitive and imaginative manner, but guided by phenomena that had been established sufficiently securely by experimental physiology to serve as models. One of the most illuminating texts in this regard is the 1915 study entitled Instincts and Their Vicissitudes. The physiological model on which Freud's thinking was based was that of stimulus and response, the sensorimotor reflex arc. To this was added another physiological assumption: 'The nervous system is an apparatus which has the function of getting rid of the stimuli that reach it, or of reducing them to the lowest possible level; or which, if it were feasible, would maintain itself in an altogether unstimulated condition. ${ }^{\text {'29 }}$

On the basis of these assumptions, Freud established a distinction (a distinction already largely foreshadowed in the writings of nineteenth-century physiologists on instincts and passions) between external excitation, which is usually unique and momentary, and internal excitation, of somatic origin, which acts 'as a constant force', whose effect is translated as 'need', and whose satisfaction, whose 'mastery', cannot be carried out according to a single muscular response, such as flight, which would constitute the adequate response to the external excitation. Not only does the instinct derive from a somatic source, but its satisfaction can be obtained only by a set of actions directed toward the exterior. The individual must bring into play a series of complex behavior patterns, the aim of which is to modify (to reduce) 'the internal source of excitation'.

Where the dream was concerned, the 'somatic source' was optional. Where instincts were concerned, there was no question of its central role. But Freud, while conceding it precedence by right, by the status of a necessary condition and a material cause, in fact declared it to be irrelevant to the psychological investigation. At this level, physiology would have been in command had it not been (provisionally? definitively?) disarmed; as for psychology, it cannot say much.

By the source of an instinct is meant the somatic process which occurs in an organ or part of the body and whose stimulus is represented in mental life by an instinct. We do not know whether this process is invariably of a chemical nature or whether it may also correspond to the release of other, e.g. mechanical, forces. The study of the sources of instincts lies outside the scope of psychology. Although instincts are wholly determined by their origin in a somatic source, in mental life we know them only by their aims. An exact knowledge of the sources of an instinct is not invariably necessary for purposes of psychological investigation; sometimes its source may be inferred from its aim. ${ }^{30}$

First remark: The transition from somatic to psychic, in the case of the instinct, is not the perceptive order; the instinct is not simply the cry of the organ echoed and recorded. At least Freud does not lay any emphasis on this element, which would immediately raise the question of its more or less conscious character. The concept he used was that of representation (repräsentieren), which implies an operation of a 'semiotic' nature. This foreshadows the 'second topic', in which the id can be seen to take on a good part of this representative function.

Second remark: Contrary to what happened with the dream, the somatic source is regained at the end of the instinctual activity, since the aim of the instinct is a modification in the source of excitation. But this aim, at first held to be invariable, can have others substituted for it. Thus the 'physiological' return to the somatic source does not take place. That phenomenon, displacing the site of satisfaction creates to some extent an illusory body which has nothing to do with the true (organic) body.

The aim of an instinct is in every instance satisfaction, which can only be obtained by removing the state of stimulation at the source of the instinct. But although the ultimate aim of each instinct remains unchangeable, there may yet be different paths leading to the same ultimate aim; so that an instinct may be found to have various nearer or intermediate aims, which are combined or interchanged with one another. Experience permits us also to speak of instincts which are 'inhibited in their aim', in the case of processes which are allowed to make some advance toward instinctual satisfaction but are then inhibited or 
deflected. We may suppose that even processes of this kind involve a partial satisfaction ${ }^{31}$.

If 'inhibition in their aim' implies a relative avoidance of the normal bodily satisfaction, a sidetracking or diversion in relation to the necessary 'modification of the source', consideration of the object of the instinct brings up a number of substitute possibilities, among which our 'own body' is called upon to play a major role.

The object of an instinct is the thing in regard to which or through which the instinct is able to achieve its aim. It is what is most variable about an instinct and is not originally connected with it, but becomes assigned to it only in consequence of being peculiarly fitted to make satisfaction possible. The object is not necessarily something extraneous: it may equally well be a part of the subject's own body. It may be changed any number of times in the course of the vicissitudes which the instinct undergoes during its existence; and highly important parts are played by this displacement of instinct. ${ }^{32}$

Our 'own body' thus appears, in the wideopen repertoire of places (that in which) or of means (that by means of which) that the instinct can choose in order to obtain its aim and on which it can on occasion become fixated. That is the case when there occurs - as in narcissism or masochism - a 'turning around of an instinct upon the subject's own self'.

Thus there appears a new role for the body; I was about to say a new body - the body as support for fixation or investment. And there is nothing to stop a new representation, prolonging or transforming that in which the somatic excitation has already been prolonged or transformed. We have not left the body. But if it is true that there persisted, for Freud, a distant analogy between the simple reflex arc and the way in which instincts work, then one could say that the body-object, the body of investment, corresponds to a motor performance, which seeks immediate confirmation in the order of perceptions, without being able to avoid getting mixed up in a whole imaginary or symbolic projection. When Schilder ${ }^{33}$ came to study the image of the body, he paid very little attention to the primary bodily schema, as derives from the different kinesthetic or somesthetic apparatuses; he was much more concerned with the image, in part fantasized, that accompanies the different types of libidinal investment. What Freud established, through a system of representations taking over one from the other, was a circuit that could renew itself virtually infinitely: from the body as the source of the instinct to the body as aim, site or means of 'satisfaction'.

All that I have done here is to recall, in a very simplified form, the essential characteristics that make it possible to place Freud's thinking in the history of ideas about cenesthesia and bodily sensations. His contribution was considerable: before him, cenesthesia was the first stage of a system of sensory information, from which sprang the personality, fully armed. Whether conscious or unconscious, these physiological data exercised their full power straightaway. All that remained to the higher centers was to submit to their law, or to respond as best they could; the traditional model included two terms, in relation to reciprocity. Traditional medical thinking used to be able to make only this simple account, reiterated in innumerable nineteenthcentury works, which started in visceral irritation and ended in, for instance, mania (or vice versa), or started in a break in the apparatus of the somatic sensibilities and ended in depersonalization. In Freud, instincts had a goal and gave rise to much longer and more circumstantial accounts, as he pursued their migrations, their substitutions and the meshing of different aims or objects. It was now a complex circuit that had to be considered, and no longer a simple short shuttling between 'action' and 'reaction'. The feeling of depersonalization, for instance, is a loss that occurs at the end of a long process; Mourning and Melancholia traces the various stages, in which the first false step is the choice of a narcissistic object. It has no relation to the primary organic and sensory dysfunction that Ribot thought to discern.

At the beginning of this essay, I almost suggested a synonymity between cenesthesia and awareness of the body. But after our rapid rereading of Freud, and recalling what he said about the "turning around of an instinct upon the subject's own self' in narcissism and masochism, there is a question that cannot be avoided : Where do we draw the line between cenesthesia, which must be a basic assumption of every human existence, and body awareness, which 
would be the hypochondriacal or perverse consequence of a narcissistic or autoerotic investment?

Sartre (who is, through Dumas, so close to Ribot's ideas) would answer without a moment's hesitation that the manner in which we 'exist our contingency' reveals itself to us in cenesthesia.

When no pain, no specific satisfaction or dissatisfaction is 'existed' by consciousness, the for-itself does not thereby cease to project itself beyond a contingency which is pure and so to speak unqualified. Consciousness does not cease 'to have' a body. Cenesthetic affectivity is, then, a pure, nonpositional apprehension of a contingency without color, a pure apprehension of the self as a factual existence. This perpetual apprehension on the part of my for-itself of an insipid taste which I cannot place, which accompanies me even in my efforts to get away from it, and which is $m y$ taste - this is what we have described elsewhere under the name of Nausea. A dull and inescapable nausea reveals my body to my consciousness $^{34}$.

As for Merleau-Ponty, the discussion of the notion of the bodily schema leads him to assert that 'one's own body is the third term, always tacitly understood, in the figure-background structure, and every figure stands out against the double horizon of external and bodily space'. ${ }^{35}$ But if to this inevitable and naive presence of the body - a 'nonpositional' (Sartre), 'tacit' (Merleau-Ponty) presence - is added an intentional awareness, it is then appropriate to ask, with Freud, whether this interest presupposes a regressive or narcissistic libidinal investment. What I devote to an awareness of the body, I subtract from my presence in the world, from my investments in the other. In a conscious awareness of the body, the aesthetic element of cenesthesia is in the nature of an instinctual satisfaction undeniably confused with primary physiological information. It is a variation on 'turning around upon the subject's own self'. There is nothing very bold in drawing the only superficially banal conclusion that the present infatuation with the different modes of body consciousness is a symptom of the considerable narcissistic component characteristic of contemporary Western culture. I am, I know, far from being the first to say so. The so-called Chicago school, Richard Sennett, ${ }^{36}$ and a variety of others have made such a declaration, based on other premises, a recurrent motif in their critical thought. Perhaps one could also enter a plea on behalf of Narcissus (or at least invoke extenuating circumstances in his favor). In a world in which technological mastery has made such rapid strides, can one not understand that the desire to feel-and to feel oneself - should arise as a compensation, necessary, even in its excesses, to our psychic survival?

\section{NOTES}

1 Paul Valéry, Cahiers (Paris: Pléiade, 1973), vol. 1, p. 1126.

2 Cf. Robert Brain, The Decorated Body (New York: Harper \& Row, 1979); Victoria Ebin, The Body Decorated (Thames and Hudson, 1979).

3 Cicero, Academica 2.24.

4 Montaigne, Essais (Paris: Presses Universitaires de France, 1965), p. 587.

5 Aristotle, De anima 3.2.

6 Descartes, Traité des passions de Tâme, in Descartes' Philosophical Writings, trans. Norman Kemp Smith (London: Macmillan, 1953), p. 290.

$7 \mathrm{Cf}$. Georges Gusdorf, Naissance de la conscience romantique au siècle des lumières (Paris, 1976), pp. 285-316.

8 'Coenasthesis, dissertatio [...] quam praeside $\mathrm{J}$. C. Reil, pro gradu doctoris defendit Chr. Friedr. Hübner' (Halle, 1974).

9 On the history of the concept of cenesthesia in the nineteenth century, cf. Jean Starobinski, 'Le Concept de cénestheśie et les idées neuropsychologiques de Moritz Schiff,' Genserus 34 (1977), fasc. $1 / 2$, pp. 2-20.

10 Carl Wernicke, Grundriss der Psychiatrie, 2nd ed. (Leipzig, 1906).

11 Ribot, The Diseases of the Personality (Chicago, 1891), p. 5.

12 Ibid., pp. 5-6.

13 Ibid., p. 30.

14 Hippolyte Taine, De Pintelligence, 12th ed. (Paris, 1911), vol. 2, p. 474.

15 Ribot, Diseases of the Personality, pp. 19-20.

16 Ibid., p. 157.

17 Notably in Problèmes de psychologie affective (Paris, 1906), p. 26.

18 Pierre Janet, De Tangoisse à Textase, 2 vols. (1926; new ed. Paris, 1975), vol. 2, chs. 1 and 2.

19 Janet, De langoisee à lextase, vol. $2, \mathrm{ch} .2$, sec. 8 , p. 71.

20 Ernest Dupré, Pathologie de Timagination et de Témotivité (Paris, 1925), pp. 289-304.

21 Charles Blondel, La conscience morbide (Paris, 1914), p. 264. The quotation refers back to Durkheim, The Elementary Forms of the Religious Life, trans. J. W. Swain (London, 1915), p. 271. 
22 See, among others, Ted Polhemus, ed., Social Aspects of the Human Body (London: Penguin, 1978); Jonathan Benthall and Ted Polhemus, eds., The Body as a Medium of Expression (Londom: Allen Lane/Penguin Books, 1975).

23 Blondel, La conscience morbide, pp. 259-260.

24 Ribot, Diseases of the Personality, p. 25.

25 Sigmund Freud, The Interpretation of Dreams, trans. J. Strachey (London, 1955), p. 39.

26 Ibid., p. 226.

27 Ibid., p. 237.

28 Ibid., p. 236.

29 Sigmund Freud, Instincts and Their Vicissitudes, in The Standard Edition of the Complete Psychological Works of Sigmund Freud, trans, J. Strachey (London, 1964), vol. 15, p. 120.
30 Ibid., p. 123.

31 Ibid., p. 122.

32 Ibid., pp. 122-123.

33 Paul Schilder, The Image and Appearance of the Human Body, Psyche Monographs: No 4 London, Kegan Paul, 1935.

34 Jean-Paul Sartre, Being and Nothingness, trans. Hazel E. Barnes (London: Methuen, 1967), p. 338.

35 Maurice Merleau-Ponty, Phenomenology of Perception, trans. Colin Smith (London: Routledge, Kegan \& Paul, 1962), p. 101.

36 Richard Sennett, 'Le narcissisme et la culture moderne,' in Former lhomme, Rencontres Internationales de Genève (Neuchâtel, La Baconnière, 1979), pp. 187-203. 